\title{
Assessment of Eptifibatide Dosing in Renal Impairment Before and After In-Service Education Provided by Pharmacists
}

\author{
Jennifer L. Donovan, PharmD; Walter S. Schroeder, PharmD; Maichi T. Tran, PharmD; \\ Keith Foster, PharmD; Alan Forrest, PharmD; Tamara B. Lee, PharmD; and Pritesh J. Gandhi, PharmD
}

\begin{abstract}
BACKGROUND: Anticoagulant and antithrombotic agents are frequently cited as sources of medication errors. Several factors increase the risk of receiving excess dosing of glycoprotein Ilb/Illa inhibitors in the management of acute coronary syndrome (ACS), including older age, female gender, elevated serum creatinine, a history of diabetes mellitus, and a history of heart failure. In June 2003, the manufacturer of eptifibatide released a recommendation adjusting infusion rate downward to $1 \mathrm{mcg}$ per $\mathrm{kg}$ per minute for eptifibatide in patients with renal impairment, defined as an estimated creatinine clearance $(\mathrm{CrCl})<50 \mathrm{ml}$ per minute. Eptifibatide is known to accumulate in patients with renal impairment, thereby increasing hemorrhagic risk.
\end{abstract}

OBJECTIVE: To assess the impact of education on physician adherence to the renal dosing recommendation for eptifibatide at 2 academic medical centers. The primary outcome measure was the proportion of patients with renal impairment dosed appropriately with eptifibatide before and after in-service education provided by a clinical pharmacist. Secondary outcome measures included the difference in the improvement in dosing adherence between the 2 sites and the influence of patient variables on the incidence of bleeding events.

METHODS: This prospective study was conducted in patients with renal impairment who received eptifibatide for the medical management of unstable angina (UA) or non-ST-elevation myocardial infarction (NSTEMI) or for the interventional management of chronic stable angina, UA, NSTEMI, or ST-elevation myocardial infarction (STEMI, not a Food and Drug Administration-approved use). Patient data were assessed at 2 tertiary care teaching institutions between June 2003 and December 2005. The preeducation phase for the sites ran from June 2003 through April 2005 for Site A and from June 2003 through May 2005 for Site B. The posteducation phase ran from May 2005 through December 2005 for Site A and from June 2005 through December 2005 for Site B.

At site A, a 1-hour educational seminar on ACS management strategies was employed, in which 5 minutes focused on adherence of prescribers to the guideline for renal dosing recommendations for eptifibatide. This tutorial was accomplished through (1) an in-service provided by 1 clinical pharmacist to the cardiology department, and (2) handouts containing the renal dosing recommendations for eptifibatide along with dosing for other medications used to manage ACS.

The intervention at Site B involved an eptifibatide-focused seminar presented to cardiologists by a clinical pharmacist, 10 minutes of which was devoted to renal dosing recommendations that included (1) a summary of literature supporting the infusion rate reduction in patients with renal impairment and (2) the specific updated dosing recommendation for eptifibatide. The data collected in retrospective chart review included patient demographics, baseline laboratory values, and risk factors for bleeding. An appropriate eptifibatide dose was defined as a physician order for a continuous infusion of $1 \mathrm{mcg}$ per $\mathrm{kg}$ per minute in patients with an estimated $\mathrm{CrCl}<50 \mathrm{ml}$ per minute.

RESULTS: A total of 148 patients with renal impairment who received eptifibatide were evaluated (106 in the preeducation phase and 42 in the posteducation phase). A significant increase in the adherence rate for eptifibatide dosing in patients with renal impairment was observed from $36.8 \%$ in the preeducation phase to $69.0 \%$ in the posteducation phase $(P<0.001)$ for the 2 sites combined. The incidence of major and minor bleeding was $16.7 \%$ in the preeducation phase and $14.3 \%$ in the posteducation phase $(P=0.742)$. When bleeding incidence was stratified by the appropriateness of infusion, the incidence of major and minor bleeding was also similar for appropriate dosing (1 mcg per kg per minute, 16.4\%) versus inappropriate dosing (2 mcg per kg per minute, $15.7 \% ; P=0.916)$.

CONCLUSION: This educational intervention provided by a clinical pharmacist was associated with improved prescriber adherence to dosing recommendations for eptifibatide in patients with renal impairment. Improved adherence to the dosing guideline and administration of an appropriate infusion rate were not associated with reduction in either minor or major bleeding events.

KEYWORDS: Eptifibatide, Dosing guideline, Renal impairment, Educational intervention, Clinical pharmacist

J Manag Care Pharm. 2007;13(7):598-606

Copyright@ 2007, Academy of Managed Care Pharmacy. All rights reserved.

\section{What is already known about this subject}

- Use of platelet glycoprotein IIb/IIla inhibitors in patients with non-ST-segment-elevation ACS reduces ischemic complications before and after percutaneous coronary intervention but is associated with an increased risk of bleeding, and even greater hemorrhagic risk has been reported in patients with renal impairment.

- The acute nature in which eptifibatide is prepared and administered in the cardiac catheterization laboratory or emergency department does not permit pharmacist evaluation or the use of a computerized dosing system.

- There are 2 common types of interventions intended to improve adherence to medication dosing guidelines: education programs and computerized dosing aids.

\section{What this study adds}

- This intervention involving pharmacist-directed education of prescribers to reduce the dose of eptifibatide to $1 \mathrm{mcg}$ per $\mathrm{kg}$ per minute for patients with renal impairment was associated with improved adherence to the dosing recommendation (the intermediate, process outcome) but no change in the proportion of patients who experienced major or minor bleeding episodes (end point, clinical outcome). These results cannot be attributed to the intervention, since this study lacked a control group. 
$\mathrm{M}$ edication errors constitute a major problem in hospitalized patients and are associated with increased morbidity and mortality.1,2 The Institute of Medicine reported in 1999 that more than 98,000 people die each year as a result of medication errors. ${ }^{3}$ Furthermore, preventable adverse drug events (ADEs) are associated with a 4.6-day increase in a hospital stay with an estimated annual cost of $\$ 2.8$ million for a 700-bed institution. ${ }^{1-4}$

Anticoagulant and antithrombotic agents are cited as frequent sources of these medication errors.1,5 The Institute of Safe Medication Practices has classified antithrombotic agents as high-alert medications because of their potential to cause significant patient harm. ${ }^{6}$ In a study by Fanikos and colleagues, anticoagulant drugs represented $7.2 \%$ of all medication errors; anticoagulants accounted for 1.72 of a total of 24 medication errors per 10,000 patient-days. ${ }^{5}$ Similarly, in a retrospective study, Saxer and colleagues compared actual doses of lepirudin with guideline-recommended doses in patients with heparin-induced thrombocytopenia and renal insufficiency. ${ }^{7}$ The authors found that $67 \%$ of patients who experienced a major bleeding event during therapy received a greater than recommended initial infusion rate.

More recently, CRUSADE (Can Rapid Risk Stratification of Unstable Angina Patients Suppress Adverse Outcomes With Early Implementation of the American College of Cardiology/American Heart Association Guidelines) investigators studied excess dosing of unfractionated heparin (UFH), low-molecular-weight heparin (LMWH), and the glycoprotein IIb/IIIa inhibitors (eptifibatide [Integrilin] and tirofiban [Aggrastat]) in non-ST-elevation acute coronary syndrome (ACS). ${ }^{8}$ Excess dosing was found in $32.8 \%$ of UFH patients ( $\mathrm{n}=2,934), 13.8 \%$ of LMWH patients ( $\mathrm{n}=1,378$ ), and $26.8 \%$ of glycoprotein IIb/IIIa inhibitor patients $(n=2,784)$. The CRUSADE investigators identified several patient characteristics that were associated with excess dosing of the glycoprotein IIb/IIIa inhibitors: age $\geq 75$ years (odds ratio [OR] = 14.39, 95\% confidence interval (CI), 12.24-16.90); female gender $(\mathrm{OR}=3.74,95 \% \mathrm{CI}, 3.29-4.25)$; serum creatinine $>2 \mathrm{mg}$ per $\mathrm{dL}$ $(\mathrm{OR}=4.12,95 \% \mathrm{CI}, 2.95-5.75)$; a history of diabetes mellitus $(\mathrm{OR}=1.35,95 \% \mathrm{CI}, 1.20-1.51)$; and a history of heart failure $(\mathrm{OR}=1.49,95 \% \mathrm{CI}, 1.23-1.81)$.

Major bleeding occurred in $17.5 \%$ of patients $(n=374)$ with excess glycoprotein IIb/IIIa inhibitor dosing. Mortality was correlated with the degree of renal impairment in patients who received excess dosing of glycoprotein IIb/IIIa inhibitors. For eptifibatide, excess dosing was defined as full dose and creatinine clearance $(\mathrm{CrCl})<50 \mathrm{ml}$ per minute, and for tirofiban, excess dosing was defined as full dose and $\mathrm{CrCl}<30 \mathrm{ml}$ per minute. Mortality was $1.2 \%(\mathrm{n}=73)$ for patients who received recommended doses of glycoprotein IIb/IIIa inhibitors compared with $4.3 \%(n=83)$ for mild excess dosing (serum creatinine $\leq 2 \mathrm{mg}$ per $\mathrm{dL}$ ) and $12.4 \%(\mathrm{n}=22)$ for major excess dosing (serum cre- atinine $>2 \mathrm{mg}$ per $\mathrm{dL}, P<0.001)$. Higher mortality persisted after adjustment (adjusted $\mathrm{OR}=1.50 ; 95 \% \mathrm{CI}, 1.03-2.17$ ). Length of hospital stay was also prolonged in patients who received excessive doses of glycoprotein IIb/IIla inhibitors to 5.2 days compared with 3.8 days for patients who did not receive excessive doses $(P<0.001)$.

In addition to the findings of the CRUSADE investigators, several articles described the incidence and cost implications of ADEs. Dosing errors were frequently identified as a major preventable ADE. Although the classes of medications varied widely, anticoagulants were frequently cited as the culprit of preventable ADE.4,9,10 Despite articles describing the frequency and preventability of ADE associated with anticoagulant and antiplatelet agents, no literature describes the impact of pharmacy-driven education to improve dosing adherence by physicians for these agents in the management of ACS. Because of this lack of data, we developed formal education programs for our health care professionals on appropriate dosing of eptifibatide, a glycoprotein IIb/IIIa inhibitor, in patients with renal insufficiency.

The purpose of this study was to compare the dosing appropriateness of eptifibatide in patients with renal impairment before and after education programs at 2 academic medical centers. This study was approved by the institutional review boards at both institutions.

\section{Methods}

\section{Patients}

We proposed that pharmacy-driven education at 2 academic medical centers would improve adherence to renal dosing recommendations for eptifibatide. On the basis of the eptifibatide package insert, patients with an estimated $\mathrm{CrCl}<50 \mathrm{ml}$ per minute require a $50 \%$ reduction in the continuous infusion rate, from $2 \mathrm{mcg}$ per $\mathrm{kg}$ per minute to $1 \mathrm{mcg}$ per $\mathrm{kg}$ per minute with no changes to the bolus dose $\left(180 \mathrm{mcg}\right.$ per $\mathrm{kg}$ ). ${ }^{11}$ Eptifibatide remains contraindicated in patients on hemodialysis. These recommendations provided the basis for our inclusion and exclusion criteria.

Patients were eligible for inclusion if they received eptifibatide for the medical management of unstable angina (UA) or non-ST-elevation myocardial infarction (NSTEMI), or as adjunct therapy in percutaneous coronary intervention for chronic stable angina (CSA), UA, NSTEMI, or ST-elevation myocardial infarction (STEMI). Eptifibatide is approved by the US Food and Drug Administration (FDA) for the medical management of UA and NSTEMI, as well as the interventional management of CSA, UA, and NSTEMI. Administration of eptifibatide in STEMI is not an FDA-approved indication and therefore represents off-label use. However, eptifibatide use as an adjunct to the interventional management of STEMI is given a Grade IIb recommendation where "treatment may be considered" by the 2005 American Heart Association (AHA)/American College of Cardiology (ACC)/ 
Society for Cardiovascular Angiography and Interventions guideline update for percutaneous coronary intervention and the 2004 AHA/ACC guideline update for the management of STEMI.12,13 Additional inclusion criteria were age $\geq 18$ years and an estimated $\mathrm{CrCl}<50 \mathrm{ml}$ per minute, as calculated by the Cockcroft and Gault equation. ${ }^{14}$ Actual body weight was used in the calculation of $\mathrm{CrCl}$, according to the recommendation from Millennium Pharmaceuticals. $\mathrm{CrCl}$ was calculated from values closest to, but not following, eptifibatide initiation. We excluded patients if fibrinolytic therapy was administered within 48 hours preceding eptifibatide administration. All patients receiving eptifibatide during the pre- and posteducation phases were assessed for inclusion, using the inclusion/exclusion criteria described above.

\section{Study Design}

The study was divided into 2 phases: the preeducation phase and the posteducation phase. In the preeducation phase, we performed a retrospective eptifibatide utilization evaluation to identify eligible patients from June 2003 through April 2005 for Site A and from June 2003 through May 2005 for Site B. June 2003 was selected as the starting date because it correlated with the release of the renal dosing recommendations. We reviewed medical records to abstract patients' age, gender, comorbidities, concomitant antiplatelet/anticoagulant medications, renal function before administration of eptifibatide, hematologic status, blood product transfusions, and eptifibatide dose administered. These data are summarized in Table 1. The actual eptifibatide dose was compared with the recommended renal dosing guideline for appropriateness, defined as a physician order for a continuous infusion of $1 \mathrm{mcg}$ per kg per minute in patients with an estimated $\mathrm{CrCl}$ $<50 \mathrm{ml}$ per minute. The preeducation and posteducation phases used the same inclusion criteria, exclusion criteria, and methods of patient identification and data abstraction. The eptifibatide utilization evaluation in the posteducation phase was conducted from May through December 2005 for Site A and from June through December 2005 for Site B.

\section{Education Programs}

The 2 sites used slightly different educational interventions for eptifibatide dosing. Site A incorporated the updated dosing recommendations as part of a larger seminar on ACS, whereas Site B provided an eptifibatide-focused seminar. Both sites developed an ACS treatment pathway that included all appropriate therapeutic options and incorporated dosing and monitoring recommendations. The education regarding the reduced dose for eptifibatide in patients with renal impairment took place at Site A in April 2005 and at Site B in May 2005.

The educational intervention at Site A included a 1-hour seminar on ACS management strategies. The in-service presentation by 1 clinical pharmacist focused on the recommendations from the CRUSADE trial, which recommends aggressive and early antiplatelet and anticoagulant therapy for patients presenting with ACS.
Review of the renal dosing of eptifibatide occurred over 5 minutes during the presentation and covered the infusion rate adjustment and the use of $\mathrm{CrCl}$ in identifying an appropriate infusion rate. A pocket reference card that included renal dosing recommendations for eptifibatide was distributed. The in-service presentation at Site A was attended by approximately $80 \%$ of the cardiology department and included cardiologists, nurses, and house officers.

The intervention at Site B employed a 10-minute eptifibatidefocused educational program. One lecture was provided to the interventional and clinical cardiologists by 1 clinical pharmacist who described eptifibatide renal dosing recommendations in the medical management of UA and NSTEMI and the interventional management of CSA, UA, NSTEMI, and STEMI. This seminar detailed the results from the ESPRIT (Enhanced Suppression of the Platelet IIb/IIIa Receptor With Integrilin Therapy) trial and Gretler and colleagues' pharmacokinetic assessment of eptifibatide in patients with renal impairment. ${ }^{15,16}$ These studies provided the data to update the renal dosing recommendation for eptifibatide. The seminar concluded with a review of the Cockcroft-Gault equation to calculate an estimated $\mathrm{CrCl}$. Physicians were given a handout of the information covered along with phone numbers to contact the central pharmacy to assist them with calculating an estimated $\mathrm{CrCl}$. Approximately $67 \%$ of the cardiologists attended this inservice presentation at Site B.

\section{Outcomes}

The primary outcome measure was the overall adherence rate to eptifibatide renal dosing recommendations pre- and posteducation. Adherence to the dosing recommendation was defined as a physician order for a continuous infusion of $1 \mathrm{mcg}$ per $\mathrm{kg}$ per minute in patients with an estimated $\mathrm{CrCl}<50 \mathrm{ml}$ per minute. Our secondary outcome measure was the difference in adherence rates between Site A and Site B to identify differences in the effectiveness of the educational programs. The safety outcome measure was the number of hemorrhagic events observed pre- and posteducation and as a function of infusion appropriateness.

Independent, patient-specific variables were also assessed for their association with bleeding events. The incidence of hemorrhage was defined and stratified based on the criteria defined by the Thrombolysis In Myocardial Infarction (TIMI) study group. ${ }^{17}$ Minor bleeding was defined as overt bleeding associated with a decrease in hemoglobin between $3 \mathrm{~g}$ and $5 \mathrm{~g}$ per dL or a 9\%-15\% decrease in hematocrit. Major bleeding was defined as an intracranial hemorrhage or overt bleeding associated with a decrease in hemoglobin $>5$ g per $\mathrm{dL}$ or $>15 \%$ decrease in hematocrit. Any bleeding was defined as the composite of minor and major bleeding.

To account for transfusions of packed red blood cells, the absolute number of units transfused was added to the difference between the baseline hemoglobin and the posttransfusion hemoglobin to obtain a true reflection of blood loss to be strati- 


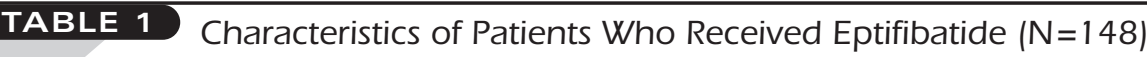

\begin{tabular}{|c|c|c|c|}
\hline & Preeducation $\mathrm{n}=106$ & Posteducation $\mathrm{N}=42$ & $P$ Value* \\
\hline Number (\%) of patients at Site A & $77(72.6)$ & $29(69.0)$ & - \\
\hline Number (\%) of patients at Site B & $29(27.4)$ & $13(31.0)$ & - \\
\hline Age (years) - mean [SD] & $75.6[9.6]$ & $77.8[9.1]$ & 0.159 \\
\hline Number of females (\%) & $49(46.2)$ & $19(45.2)$ & 1.000 \\
\hline Actual weight $(\mathrm{kg})$ - median [SD] & $74[15.4]$ & $70[13.7]$ & 0.074 \\
\hline Length of stay (days) - mean [SD] & $7.8[8.0]$ & $6.4[6.2]$ & 0.329 \\
\hline \multicolumn{4}{|l|}{ Indication for eptifibatide - n (\%) } \\
\hline Chronic stable angina & $10(9.4)$ & $8(19.0)$ & 0.177 \\
\hline Unstable angina & $31(29.2)$ & $0(0)$ & $<0.001$ \\
\hline NSTEMI & $46(43.3)$ & $20(47.6)$ & 0.714 \\
\hline STEMI & $19(17.9)$ & $14(33.3)$ & 0.050 \\
\hline \multicolumn{4}{|l|}{ Past medical history - $\mathbf{n}(\%)$} \\
\hline Coronary artery disease & $82(77.3)$ & $27(64.2)$ & 0.146 \\
\hline Diabetes mellitus & $46(43.3)$ & $18(42.8)$ & 1.000 \\
\hline Heart failure & $31(29.2)$ & $13(31.0)$ & 0.692 \\
\hline Cerebral vascular disease & $8(7.5)$ & $2(4.7)$ & 0.725 \\
\hline Peripheral vascular disease & $19(17.9)$ & $5(11.9)$ & 0.463 \\
\hline Chronic renal failure & $50(47.1)$ & $23(54.7)$ & 0.467 \\
\hline Average comorbidities per patient [SD] & $2.3[1.2]$ & $2.1[1.2]$ & 0.517 \\
\hline \multicolumn{4}{|l|}{ Concurrent medications - n (\%) } \\
\hline Aspirin & $98(92.4)$ & $41(97.6)$ & 0.446 \\
\hline Clopidogrel & $87(82.0)$ & $38(90.4)$ & 0.313 \\
\hline Unfractionated heparin & $106(100)$ & $41(97.6)$ & 0.284 \\
\hline Enoxaparin & $6(5.6)$ & $2(4.7)$ & 1.000 \\
\hline Warfarin & $2(1.8)$ & $3(7.1)$ & 0.138 \\
\hline Nonsteroidal inflammatory agent & $4(3.7)$ & $1(2.4)$ & 1.000 \\
\hline Average no. medications per patient [SD] & $2.9[0.64]$ & $3.0[0.54]$ & 0.819 \\
\hline \multicolumn{4}{|l|}{ Laboratory data } \\
\hline Baseline serum creatinine (mg per dL) [SD] & $2.1[1.11]$ & $2.2[1.67]$ & 0.635 \\
\hline Baseline $\mathrm{CrCl}$ (ml per minute) [SD] & $33.8[9.45]$ & $30.2[9.6]$ & 0.039 \\
\hline Baseline hemoglobin (g per dL) [SD] & $11.8[1.86]$ & $11.6[1.55]$ & 0.504 \\
\hline
\end{tabular}

* Continuous variables were assessed via the Wilcoxon rank sum test. Comparisons of dichotomous variables were assessed by either the Fisher exact test or Pearson chi-square test depending on the expected value in each of the 4 cells.

$\mathrm{CrCl}=$ creatinine clearance; $\mathrm{NSTEMI}=$ non-ST-elevation myocardial infarction; STEMI=ST-segment-elevation myocardial infarction.

fied by the criteria above. Bleeding assessments were performed by reviewing laboratory data and chart review for annotations of overt or intracranial bleeding.

\section{Statistical Analysis}

Summary statistics, including 1-way and 2-way contingency tables, were computed for initial exploratory analyses. In the 2-group analysis, continuous variables were assessed via the Wilcoxon rank sum test. Dichotomous comparisons, including eptifibatide dosing adherence rates in the pre- and posteducation phases and bleeding incidence as a function of education and infusion appropriateness, were assessed by either the Fisher exact test or the Pearson chi-square test, depending on the expected value in each of the 4 cells. 
Two logistic regression analyses were conducted. In the first analysis, the adherence rate (dependent variable) was assessed as a function of the study site and educational phase (independent variables) using multivariate, multinomial logistic regression with backwards stepping. Study site and educational phase were selected as independent variables to determine if the educational interventions conducted at the study sites were associated with a difference in dosing adherence. We did not include patient characteristics as covariates in this equation because our focus was to determine the impact of the educational program as opposed to factors contributing to excess dosing.

In the second logistic regression analysis, the bleeding rate (dependent variable) was assessed as a function of infusion appropriateness by the independent variables; percentage above ideal body weight; hours of eptifibatide infused; age $>80$ years; weight $<65 \mathrm{~kg} ; \mathrm{CrCl} \leq 30 \mathrm{ml}$ per minute; female gender; use of aspirin, clopidogrel, UFH, enoxaparin, warfarin, or nonsteroidal anti-inflammatory drugs; or a history of coronary artery disease, chronic renal failure, cerebrovascular disease, peripheral vascular disease, abdominal aortic aneurysm, heart failure, or diabetes, using multivariable, multinomial logistic regression with backwards stepping. The independent variables were selected for logistic regression analysis for bleeding to determine if established risk factors associated with increasing bleeding risk as well as other cardiovascular comorbidities were associated with an increased likelihood of a hemorrhagic event. Continuous independent variables, including percentage above ideal body weight, hours of eptifibatide infusion, age, actual body weight, and $\mathrm{CrCl}$ were divided into ranges and were treated as categorical variables.

Goodness of fit for logistic regression analysis was assessed using the McFadden's rho-squared statistic, analogous to an $R^{2}$. Analyses were performed using Systat version 11, Systat Software Inc., Richmond, California.

Patients undergoing coronary artery bypass grafting (CABG) were excluded from the bleeding analysis since intraoperative blood product use would skew the incidence of hemorrhage. Patients with incomplete data sets were excluded from logistic regression analysis, as calculations could not be performed without all tested variables.

\section{Results}

A total of 106 patients in the preeducation phase and 42 patients in the posteducation phase were included in this analysis. No differences between phases were identified with respect to age, gender, or length of hospitalization (Table 1). In addition, both groups had a similar average number of comorbidities $(P=$ 0.517). However, in the preeducation phase, significantly more patients presented with UA $(P<0.001)$. Furthermore, although statistical differences were found between groups with respect to baseline $\mathrm{CrCl}$ (preeducation phase $33.8 \mathrm{ml}$ per minute vs. posteducation phase $30.2 \mathrm{ml}$ per minute $[P=0.039]$ ); these were not clinically significant.

\section{Impact of Education on Adherence}

A significantly larger percentage of patients received an appropriate infusion of eptifibatide in the posteducation phase (69.0\%) than in the preeducation phase $(36.8 \% ; P<0.001$, Table 2$)$.

\section{Impact of Educational Program Type on Adherence}

Site A included 77 and 29 patients in the preeducation phase and the posteducation phase, respectively. Site B enrolled 29 patients in the preeducation phase and 13 in the posteducation phase. Both sites experienced a statistically significant absolute improvement in dosing adherence for eptifibatide (Site A: 31.3\%, P = 0.005 , Site B: $34.7 \%, P=0.049$; Table 2). Logistic regression of eptifibatide infusion appropriateness was assessed as a function of study phase and site. A total of 148 patients were included in this analysis. This analysis did not identify any significant relationship between study site $(\mathrm{OR}=0.98, P=0.986)$ or the interaction between site and phase $(\mathrm{OR}=1.162, P=0.860)$. The McFadden's rho-squared statistic for this analysis was 0.063 . The lack of a difference observed between the 2 sites in comparison of the preeducation and posteducation phases suggests that the 2 intervention methods had similar effects in improving the adherence to renal dosing of eptifibatide. However, the small and unequal sample sizes reduced the power to detect a difference in the educational interventions.

\section{Bleeding}

After removing data for patients who went on to $C A B G$, we included 131 patients in the initial bleeding analysis. Data for patients who received CABG were removed in accordance with the TIMI bleeding criteria, as the transfusion requirements for this population skew bleeding results. A total of 11 minor and 10 major bleeding events occurred.

Table 3 describes bleeding incidence as a function of study phase. Minor bleeding occurred in 8 patients $(8.3 \%)$ in the preeducation phase and in 3 patients $(8.6 \%)$ in the posteducation phase $(P=0.965)$. Major bleeding in the pre- and posteducation phases occurred in 8 patients $(8.3 \%)$ and 2 patients $(5.7 \%)$, respectively $(P=0.617)$. When these patients were stratified by eptifibatide infusion appropriateness, minor bleeding occurred in 5 patients $(8.2 \%)$ who received an appropriate infusion and in 6 patients $(8.6 \%)$ who received an inappropriate infusion $(P=0.939)$. Major bleeding occurred in 5 patients (8.2\%) who received an appropriate infusion and in 5 patients $(7.1 \%)$ who received an inappropriate infusion $(P=0.821)$. Table 4 summarizes the bleeding incidence as a function of infusion appropriateness.

After the initial bleeding analysis, we performed logistic regression to identify other potential risk factors for bleeding. Data summarizing the bleeding responses and patient charac- 
teristics are summarized in Table 5. Because of the large number and distribution of variables assessed and the uneven distribution of minor and major bleeding, patients were stratified as having any bleeding (minor or major) or no bleeding. As with the initial bleeding analysis, patients who received CABG were excluded from analysis. Patients who did not have complete data sets were also excluded, as logistic regression could not be performed on incomplete data sets. Most commonly, these patients did not have a height annotated for us to calculate an ideal body weight.

After these patients were removed, 119 were left for analysis. A total of 17 (8 minor, 9 major) bleeding events were identified, using the bleeding criteria established by the TIMI study group. Of the established and hypothesized risk factors for bleeding (female gender, age > 80 years; infusion appropriateness; $\mathrm{CrCl}<30 \mathrm{ml}$ per minute; a history of chronic renal failure, heart failure, or diabetes), only age $>80$ years was associated with significantly increased odds of bleeding ( $\mathrm{OR}=4.74,95 \% \mathrm{CI}$, 1.45-15.38, $P=0.010$ ). The McFadden's rho-squared statistic for this analysis was 0.101 .

\section{Discussion}

Our challenge was to develop an educational program to educate physicians not only on the updated dosing of eptifibatide, but also on the assessment of renal function in patients to determine the optimal dose. A wealth of literature exists on educational programs to increase physician awareness and recognition of disease states as well as strategies to improve prescribing of medications. However, no reports detail educational strategies to optimize the dose of medications to manage disease. Despite this limitation, we developed and applied educational strategies similar to those found in the literature to increase disease state awareness and adherence to disease state management guidelines. $18-20$

Schunemann and colleagues conducted an assessment of physician opinion regarding educational strategies to improve guideline adherence as part of the Seventh American College of Chest Physicians Conference on Antithrombotic and Thrombolytic Therapy. ${ }^{18}$ Their results identified dissemination of printed information and educational seminars as preferred methods that physicians believed would result in increased adherence. They also acknowledged active strategies, such as computerized reminders and patient-focused interventions, as established methods by which adherence may be improved.

These findings were echoed by Tooher and colleagues in their review of strategies to improve venous thromboembolism (VTE) prophylaxis. ${ }^{20}$ Their review assessed the effectiveness of educational strategies to improve prescribing of agents for VTE prophylaxis. The authors identified continuing education, audit and feedback, computer-based decision aids, documentation aids, and quality assurance strategies as among the best ways to improve prescribing of VTE prophylaxis. They further

\begin{tabular}{|c|c|c|c|}
\hline & $\begin{array}{c}\text { Preeducation Phase } \\
\text { Site A: June 2003- } \\
\text { April } 2005 \\
\text { Site B: June 2003- } \\
\text { May } 2005 \\
\text { n= } 106(\%)\end{array}$ & $\begin{array}{c}\text { Posteducation Phase } \\
\text { Site A: May 2005- } \\
\text { December 2005 } \\
\text { Site B: June 2005- } \\
\text { December 2005 } \\
\text { n =42 (\%) }\end{array}$ & $P$ Value $\dagger$ \\
\hline te A & $29(37.7)$ & $20(69.0)$ & 0.005 \\
\hline e B & $10(34.5)$ & $9(69.2)$ & 0.049 \\
\hline mbined & $39(36.8)$ & $29(69.0)$ & $<0.001$ \\
\hline
\end{tabular}

* Infusion appropriateness is defined as a physician order for a continuous infusion of $1 \mathrm{mcg}$ per $\mathrm{kg}$ per minute in patients with an estimated $\mathrm{CrCl}<50 \mathrm{ml}$ per minute. $\dagger$ For each of the 2 sites, the Pearson chi-square test was used to assess the differences in adherence rates between the preeducation and posteducation phases. $\mathrm{CrCI}=$ creatinine clearance.

TABLE 3 Overall Incidence of Bleeding ( $N=131$ *)

\begin{tabular}{l|c|c|c}
\hline & $\begin{array}{c}\text { Preeducation Phase } \\
\text { Site A: June 2003- } \\
\text { April 2005 } \\
\begin{array}{c}\text { Site B: June 2003- } \\
\text { May 2005 } \\
\mathbf{n}=96(\%)\end{array}\end{array}$ & $\begin{array}{c}\text { Posteducation Phase } \\
\text { Site A: May 2005-De- } \\
\text { cember 2005 } \\
\text { Site B: June 2005- } \\
\text { December 2005 } \\
\mathbf{n}=35(\%)\end{array}$ & P Value \\
\hline Minor $^{\ddagger}$ & $8(8.3)$ & $3(8.6)$ & 0.965 \\
\hline Major $^{\ddagger}$ & $8(8.3)$ & $2(5.7)$ & 0.617 \\
\hline Combined $^{\S}$ & $16(16.7)$ & $5(14.3)$ & 0.742 \\
\hline
\end{tabular}

* 17 patients were initially removed from the bleeding analysis because they had a coronary artery bypass graft procedure.

+ Minor bleeding is defined as overt bleeding with a decrease in hemoglobin from $3 \mathrm{~g}$ to $5 \mathrm{~g}$ per $\mathrm{dL}$ or a $9 \%-15 \%$ decrease in hematocrit.

$\$$ Major bleeding is defined as overt bleeding with a decrease in hemoglobin $>5 \mathrm{~g}$ per $d L$ or $>15 \%$ decrease in hematocrit.

Bleeding was assessed through laboratory values and through chart review.

$\S$ The Fisher exact test was used to assess the difference in bleeding incidences between the educational phases.

went on to suggest that multiple educational strategies involving active programs like computerized reminders may be more effective than a single strategy.

The incidence of minor and major bleeding events did not significantly change between the preeducation (16.7\%) and posteducation phases (14.3\%). The overall bleeding rates appeared to be elevated in comparison with rates reported by large, prospective trials evaluating the safety and efficacy of eptifibatide in patients irrespective of renal function. In the Integrilin to Minimise Platelet Aggregation and Coronary Thrombosis-II (IMPACT-II) trial, 2,682 patients were ran- 


\begin{tabular}{|c|c|c|c|}
\hline & $\begin{array}{l}\text { Appropriate Infusion } \\
\text { (1 mcg per kg } \\
\text { per Minute) } \\
n=61(\%)\end{array}$ & $\begin{array}{l}\text { Inappropriate Infusion } \\
(2 \mathrm{mcg} \text { per kg } \\
\text { per Minute }) \\
\mathrm{n}=70(\%)\end{array}$ & $P$ Value ${ }^{\S}$ \\
\hline Minor $^{\dagger}$ & $5(8.2)$ & $6(8.6)$ & 0.939 \\
\hline Major $^{\ddagger}$ & $5(8.2)$ & $5(7.1)$ & 0.821 \\
\hline Combined & $10(16.4)$ & $11(15.7)$ & 0.916 \\
\hline \multicolumn{4}{|c|}{$\begin{array}{l}\text { * } 17 \text { patients were initially removed from the bleeding analysis because they had a } \\
\text { coronary artery bypass graft procedure. } \\
\text { † Minor bleeding is defined as overt bleeding with a decrease in hemoglobin from } 3 \mathrm{~g} \\
\text { to } 5 \mathrm{~g} \text { per } \mathrm{dL} \text { or a } 9 \%-15 \% \text { decrease in hematocrit. } \\
\text { \$ Major bleeding is defined as overt bleeding with a decrease in hemoglobin }>5 \mathrm{~g} \text { per } \\
\text { dL or }>15 \% \text { decrease in hematocrit. } \\
\text { Bleeding was assessed through laboratory values and through chart review. } \\
\$ \text { The Fisher exact test was used to determine the differences in bleeding incidences } \\
\text { based on receiving an appropriate versus inappropriate infusion of eptifibatide. }\end{array}$} \\
\hline
\end{tabular}

domized to receive a $135 \mathrm{mcg}$ per $\mathrm{kg}$ bolus of eptifibatide followed by continuous infusion of $0.5 \mathrm{mcg}$ or $0.75 \mathrm{mcg}$ per $\mathrm{kg}$ per minute. ${ }^{21}$ The incidence of major bleeding was $5.1 \%$ and $5.2 \%$ in each group, respectively. The rate of major and minor bleeding in 4,679 patients who received eptifibatide as a $180 \mathrm{mcg}$ per kg per minute bolus followed by either a $1.3 \mathrm{mcg}$ or $2 \mathrm{mcg}$ per $\mathrm{kg}$ per minute infusion in the Platelet Glycopotein IIb/IIIa in Unstable Angina: Receptor Suppression Using Integrilin Therapy (PURSUIT) clinical trial was 14.0\% for the subset of patients who did not undergo CABG. ${ }^{22}$ In the 1,040 patients randomized to receive two $180 \mathrm{mcg}$ per $\mathrm{kg}$ boluses of eptifibatide followed by continuous infusion of $2 \mathrm{mcg}$ per $\mathrm{kg}$ per minute in the ESPRIT trial, $4.8 \%$ of patients experienced a mild, moderate, or severe bleeding event. 15

In all 3 studies, the authors encouraged the use of aspirin and heparin therapy as part of standard ACS care. In the PURSUIT study, 93\% of patients were administered aspirin and $89.8 \%$ of patients received heparin.22 These values are similar to aspirin and heparin use researchers found in our study (see Table 1). Data on the use of aspirin and heparin for the IMPACT-II and ESPRIT trials were not reported. The most notable variable that may explain the difference in bleeding rates between our results and these trials is the presence of renal impairment. We specifically enrolled patients with a $\mathrm{CrCl}<50 \mathrm{ml}$ per minute, whereas the IMPACT-II, PURSUIT, and ESPRIT trials enrolled patients irrespective of renal function. Furthermore, our patient population appeared to have an older mean age ( 75.6 years in the preeducation phase and 77.8 years in the posteducation phase) compared with the population in the IMPACT-II (62 years in the group receiving $0.5 \mathrm{mcg}$ per $\mathrm{kg}$ per minute and 60 in the group receiving $0.75 \mathrm{mcg}$ per kg per minute), PURSUIT (64 years), and ESPRIT (62 years) trials.15,21,22 Also, our

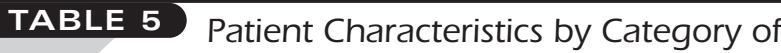 Bleeding Response $\left(\mathrm{N}=119^{*}\right)$}

\begin{tabular}{|c|c|c|}
\hline Variable & $\begin{array}{c}\text { Patients Who } \\
\text { Experienced } \\
\text { No Bleeding } \\
\mathrm{n}=102(\%) \\
\end{array}$ & $\begin{array}{c}\text { Patients Who } \\
\text { Experienced } \\
\text { Any Bleeding } \\
\mathrm{n}=17(\%) \\
\end{array}$ \\
\hline $\begin{array}{l}\text { Appropriate infusion of eptifibatide } \\
\text { (1 mcg per kg per minute) }\end{array}$ & $54(52.9)$ & $7(41.2)$ \\
\hline $\begin{array}{l}\text { Percentage above IBW } \\
\cdot<120 \% \\
\cdot 120 \%-139 \% \\
\cdot>140 \% \\
\end{array}$ & $\begin{array}{l}38(37.3) \\
36(35.3) \\
28(27.5)\end{array}$ & $\begin{array}{l}4(23.5) \\
5(29.4) \\
8(47.0)\end{array}$ \\
\hline $\begin{array}{l}\text { Hours of eptifibatide } \\
0-14.9 \\
15-17.9 \\
>18 \\
\end{array}$ & $\begin{array}{l}33(32.4) \\
38(37.3) \\
31(30.4)\end{array}$ & $\begin{array}{r}4(23.5) \\
10(58.8) \\
3(17.6) \\
\end{array}$ \\
\hline Age $\geq 80$ years $\neq$ & $38(37.3)$ & $11(64.7)$ \\
\hline Weight $<65 \mathrm{~kg}$ & $25(24.5)$ & $4(23.5)$ \\
\hline $\mathrm{CrCL} \leq 30 \mathrm{~mL}$ per minute & $37(36.3)$ & $6(35.3)$ \\
\hline Female gender & $50(49.0)$ & $6(35.3)$ \\
\hline Aspirin & $98(96.0)$ & $15(88.2)$ \\
\hline Clopidogrel & $93(91.2)$ & $15(88.2)$ \\
\hline Unfractionated heparin & $102(100)$ & $17(100)$ \\
\hline Enoxaparin & $4(3.9)$ & $3(17.6)$ \\
\hline Warfarin & $4(3.9)$ & $1(6.0)$ \\
\hline NSAID & $4(3.9)$ & 0 \\
\hline Coronary artery disease & $72(70.6)$ & $12(70.6)$ \\
\hline Chronic renal failure & $52(51.0)$ & $9(52.9)$ \\
\hline Cerebrovascular disease & $6(5.9)$ & $3(17.6)$ \\
\hline Peripheral vascular disease & $17(16.7)$ & $2(11.8)$ \\
\hline Abdominal aortic aneurysm & $5(4.9)$ & 0 \\
\hline Heart failure & $29(28.4)$ & $7(41.2)$ \\
\hline Diabetes & $49(48.0)$ & $4(23.5)$ \\
\hline
\end{tabular}

* 17 patients were initially removed from the bleeding analysis because they had a coronary artery bypass graft procedure. Logistic regression requires complete data sets for all tested variables to be valid, and 12 patients did not have documented heights to assess the percentage above ideal body weight.

$\dagger$ Any bleeding: Overt bleeding was associated with a decrease in hemoglobin $\geq 3$ g per dL or in hematocrit $\geq 9 \%$, assessed by the investigators through laboratory data and chart review.

$¥$ Odds ratio $=4.740 ; 95 \% \mathrm{CI}, 1.45-15.38 ; P=0.010$. (This variable was the only factor remaining in the multivariate, multinomial logistic regression equation after backwards stepping.)

$\mathrm{CrCL}=$ creatinine clearance; $I B W=$ ideal body weight NSAID = nonsteroidal antiinflammatory drug.

study appeared to have more female patients ( $46.2 \%$ in the preeducation phase and $45.2 \%$ in the posteducation phase) compared with the IMPACT-II (25.6\%), PURSUIT (34.9\%), and ESPRIT (27\%) 
trials. ${ }^{14,20,21}$ Last, the median weight of our patient population (74 $\mathrm{kg}$ in the preeducation phase and $70 \mathrm{~kg}$ in the posteducation phase) appeared to be lower than that in the IMPACT-II (83 $\mathrm{kg}$ in patients who received $0.5 \mathrm{mcg}$ per $\mathrm{kg}$ per minute and $84 \mathrm{~kg}$ in patients who received $0.75 \mathrm{mcg}$ per $\mathrm{kg}$ per minute), PURSUIT $(78 \mathrm{~kg}$ ), and ESPRIT trials $(84 \mathrm{~kg}) .15,21,22$ While the significance of the differences in these variables between our data and those of other researchers is unknown, our population appears to be at higher risk for receiving greater than recommended doses of eptifibatide and increased risk of bleeding associated with older patient age, a larger percentage of female patients, and lower actual body weight.

\section{Limitations}

First and foremost among the limitations of this study was the absence of a control group. Therefore, we cannot be certain that our educational intervention was the reason for the improved adherence to the dosing guideline in patients with renal impairment. Second, we chose to define the primary outcome measure as an intermediate measure (infusion appropriateness) and the proportion of patients who experienced either a major or minor bleeding episode as the secondary outcome. Our assumption was that adherence to renal dosing recommendations would result in a decrease in hemorrhagic complications.

Third, the small and unequal sample sizes in the preeducation and posteducation phases contributed to the absence of a significant difference in the incidence of minor and major hemorrhagic events in this analysis. Logistic regression demonstrated an increased likelihood of bleeding in patients $>80$ years. We anticipated an increased risk of bleeding in patients in whom eptifibatide serum concentration should be elevated (history of chronic renal failure, $\mathrm{CrCl}<30 \mathrm{ml}$ per minute, inappropriate infusion rate, prolonged infusion). However, none of these factors was associated with increasing patients' bleeding risk, most likely due to the small sample size in our study.

The pharmacokinetic study reported by Gretler and colleagues demonstrated a 2-fold increase in serum steady-state concentrations of eptifibatide and a $50 \%$ decrease in total clearance of eptifibatide in patients with a $\mathrm{CrCl}<50 \mathrm{ml}$ per minute. ${ }^{16}$ These pharmacokinetic data served as the foundation for the renal dosing recommendations for eptifibatide as opposed to actual observed bleeding rates between the cohorts of patients with renal impairment. While our study results are only descriptive, the 16\% average rate of minor and major bleeding combined for both appropriate infusion (1 mcg per kg per minute) and inappropriate infusion (2 mcg per kg per minute) suggests that further research is warranted in eptifibatide use in patients with renal impairment.

\section{Conclusion}

To our knowledge, this is the first study in which researches investigated the impact of pharmacist-driven education to improve dosing of an antiplatelet agent in the management of
ACS. The education programs were associated with improvement in the dosing of eptifibatide in patients with renal impairment to the recommended dose of $1 \mathrm{mcg}$ per $\mathrm{kg}$ per minute in $69.0 \%$ of patients compared with $36.8 \%$ before the intervention. The proportion of patients who experienced either major or minor bleeding was similar in the 2 periods, $16.7 \%$ (16 patients) in the preeducation period and $14.3 \%$ (5 patients) in the posteducation period, and there was no difference in the incidence of major or minor bleeding (approximately 16\% for both infusion rates of $1 \mathrm{mcg}$ or $2 \mathrm{mcg}$ per $\mathrm{kg}$ per minute).

\section{ACKNOWLEDGMENTS}

We extend our gratitude to Frederick Spencer, MD, and Neil Dashkoff, MD, for their valuable feedback and assistance in conducting this study.

\section{DISCLOSURES}

This study was conducted with the support of an unrestricted educational grant provided by the Schering-Plough Corporation. Jennifer Donovan is a grant recipient from Schering-Plough and GlaxoSmithKline and a speaker for SanofiAventis. Walter Schroeder is a grant recipient from Schering-Plough. Authors Maichi T. Tran, Keith Foster, Alan Forrest, Tamara B. Lee, and Pritesh J. Gandhi disclose no potential bias or conflict of interest relating to this article. Maichi Tran is a grant recipient from GlaxoSmithKline and Sanofi-Aventis.

Donovan served as principal author of the study. Study concept and design were contributed by Donovan, Schroeder, Tran, and Gandhi. Data collection was the work of Schroeder, Donovan, Foster, and Lee; data interpretation was the work of Schroeder, Donovan, Forrest, and Gandi. Writing of the manuscript and its revision were primarily the work of Schroeder and Donovan, with input from Tran, Foster, Forrest, Lee, and Gandhi.

\section{Authors}

JENNIFER L. DONOVAN, PharmD, is an assistant professor of pharmacy practice, Massachusetts College of Pharmacy and Health Sciences, Worcester, and an adjunct assistant professor of emergency medicine, University of Massachusetts Medical School, Worcester; WALTER S. SCHROEDER, PharmD, is a clinical assistant professor of pharmacy, University at Buffalo School of Pharmacy and Pharmaceutical Sciences, and a clinical assistant professor of medicine, University at Buffalo School of Medicine, New York; MAICHI T. TRAN, PharmD, is a cardiovascular pharmacotherapy specialist, University of Massachusetts Memorial Medical Center, Worcester, and an assistant professor of medicine, University of Massachusetts Medical School; KEITH FOSTER, PharmD, is a clinical pharmacist, University of Massachusetts Memorial Medical Center; ALAN FORREST, PharmD, is a research professor, University at Buffalo School of Pharmacy and Pharmaceutical Sciences; TAMARA B. LEE, PharmD, is an assistant professor, University of Southern Nevada College of Pharmacy, Henderson; PRITESH J. GANDHI, PharmD, is senior director, Medical Science Liaisons, Genzyme Corporation, Cambridge, Massachusetts.

AUTHOR CORRESPONDENCE: Walter S. Schroeder, PharmD, University at Buffalo, The State University of New York, School of Pharmacy and Pharmaceutical Sciences, Cooke Hall 317, Buffalo, NY 14260. Tel: (716) 645-3915, ext. 244; Fax: (716) 645-2886; E-mail: walt.schroeder@gmail.com 


\section{REFERENCES}

1. Bates DW, Cullen DJ, Laird N, et al. Incidence of adverse drug events and potential adverse drug events. Implications for prevention. ADE Prevention Study Group. JAMA. 1995;274:29-34.

2. Leape LL, Bates DW, Cullen DJ, et al. Systems analysis of adverse drug events. ADE Prevention Study Group. JAMA. 1995;274:35-43.

3. Kohn KT, Corrigan JM, Donaldson MS. To err is human: building a safer health system. Washington, DC: National Academy of Sciences, Institute of Medicine; 1999. Report no.: R729.8.T6 2000.

4. Bates DW, Spell N, Cullen DJ, et al. The costs of adverse drug events in hospitalized patients. ADE Prevention Study Group. JAMA. 1997;277:307-11.

5. Fanikos J, Stapinski C, Koo S, et al. Medication errors associated with anticoagulant therapy in the hospital. Am J Cardiol. 2004;94:53235.

6. Institute for Safe Medication Practices. (2007). ISMP's List of High-Alert Medications. Available at http://www.ismp.org/tools/highalertmedications.pdf. Accessed August 25, 2007.

7. Saxer SB, Smith BS, Gandhi PJ, Tataronis GR, Krikorian SA. Recommended and actual lepirudin doses in patients with renal insufficiency. Am J Health Syst Pharm. 2003;60:2588-93.

8. Alexander KP, Chen AY, Roe MT, et al. Excess dosing of antiplatelet and antithrombin agents in the treatment of non-ST-segment elevation acute coronary syndromes. JAMA. 2005;294:3108-16.

9. Classen DC, Pestotnik SL, Evans RS, Lloyd JF, Burke JP. Adverse drug events in hospitalized patients. Excess length of stay, extra costs, and attributable mortality. JAMA. 1997;277:301-06.

10. Winterstein AG, Hatton RC, Gonzalez-Rothi R, Johns TE, Segal R. Identifying clinically significant preventable adverse drug events through a hospital's database of adverse drug reaction reports. Am J Health Syst Pharm. 2002;59:1742-49.

11. Eptifibatide package insert. Kenilworth, NJ. Schering Corporation; June 2005.

12. Antman EM, Anbe DT, Armstrong PW, et al. ACC/AHA guidelines for the management of patients with ST-elevation myocardial infarction-executive summary: a report of the American College of Cardiology/American Heart Association task force on practice guidelines (writing committee to revise the 1999 guidelines for the management of patients with acute myocardial infarction). Circ. 2004;110:588-636.
13. Smith SC Jr, Feldman TE, Hirshfeld JW Jr, et al. ACC/AHA/SCAI 2005 guideline update for percutaneous coronary intervention: a report of the American College of Cardiology/American Heart Association task force on practice guidelines (ACC/AHA/SCAI writing committee to update 2001 guidelines for percutaneous coronary intervention). Circ. 2006;113:el66-e286. 14. Cockcroft DW, Gault MH. Prediction of creatinine clearance from serum creatinine. Nephron. 1976;16:31-41.

15. The ESPRIT Investigators. Novel dosing regimen of eptifibatide in planned coronary stent implantation (ESPRIT): a randomised, placebo-controlled trial. Lancet. 2000;356:2037-44.

16. Gretler DD, Guerciolini R, Williams PJ. Pharmacokinetic and pharmacodynamic properties of eptifibatide in subjects with normal or impaired renal function. Clin Ther. 2004;26:390-98.

17. Antman EM, Morrow DA, McCabe CH, et al. Enoxaparin versus unfractionated heparin as antithrombin therapy in patients receiving fibrinolysis for ST-elevation myocardial infarction. Design and rationale for the enoxaparin and thrombolysis reperfusion for acute myocardial infarction treatment-thrombolysis in myocardial infarction study 25 (ExTRACT-TIMI 25). Am Heart J. 2005;149:217-26.

18. Schunemann HJ, Cook D, Grimshaw J, et al. Antithrombotic and thrombolytic therapy: from evidence to application: the Seventh ACCP Conference on Antithrombotic and Thrombolytic Therapy. Chest. 2004;126:688S-696S.

19. Grimshaw JM, Thomas RE, MacLennan G, et al. Effectiveness and efficiency of guideline dissemination and implementation strategies. Health Technol Assess. 2004;8:iii-iv, 1-72.

20. Tooher R, Middleton P, Pham C, et al. A systematic review of strategies to improve prophylaxis for venous thromboembolism in hospitals. Ann Surg. 2005;241:397-415.

21. The IMPACT-II Investigators. Randomised placebo-controlled trial of effect of eptifibatide on complications of percutaneous coronary intervention: IMPACT-II. Integrilin to minimise platelet aggregation and coronary thrombosis (IMPACT)-II. Lancet. 1997;349:1422-28.

22. The PURSUIT Investigators. Inhibition of platelet glycoprotein IIb/IIIa with eptifibatide in patients with acute coronary syndromes. Platelet glycoprotein IIb/IIIa in unstable angina: receptor suppression using integrilin therapy (PURSUIT). N Engl J Med. 1998;339:436-43. 